\title{
Special Issue on 13th International Society of Asphalt Pavements (ISAP) Conference
}

\author{
Guest editors: \\ Jorge Barbosa Soares ${ }^{1}$, Gabriele Tebaldi², Francisco Thiago Sacramento Aragão ${ }^{3}$, \\ Kamilla Vasconcelos Savasini ${ }^{4}$, Elena Romeo ${ }^{5}$, Eshan Dave ${ }^{6}$ \\ ${ }^{1}$ Federal University of Ceará, Fortaleza, Brazil - jsoares@det.ufc.br \\ ${ }^{2}$ University of Parma, Parma, Italy - gtebaldi@unipr.it \\ ${ }^{3}$ Federal University of Rio de Janeiro, Rio de Janeiro, Brazil - fthiago@coc.ufrj.br \\ ${ }^{4}$ University of São Paulo, São Paulo, SP, Brazil - kamilla.vasconcelos@gmail.com \\ ${ }^{5}$ University of Parma, Parma, Italy - elena.romeo@unipr.it \\ ${ }^{6}$ University of New Hampshire, Durham, United States - Eshan.Dave@unh.edu
}

The International Society for Asphalt Pavements (ISAP) is a volunteer organization of professionals and experts in asphalt engineering whose goal is to share the latest in leading edge asphalt pavement technology worldwide. ISAP's most important event, its Conference, is held every four years and the 13th ISAP Conference on Asphalt Pavements (ISAP2018) took place in Fortaleza (Brazil) from June 19th to 21st 2018, for the first time in Latin America. There were participants from 25 countries presenting and debating ideas covering a wide range of topics within pavement infrastructure. Such events provide opportunities to share and learn ideas and discuss how to transform the best available knowledge into applications that can enhance people's lives, respecting the environment with an eye on future generations. ISAP promotes such diverse gatherings and helps building a creative environment to keep turning the wheel of knowledge.

This special issue of TRANSPORTES, originated from ISAP2018, provides a compilation of articles that advance the state of knowledge in the area of asphalt pavements. It contains nine original scientific papers. All articles are improved and expanded versions of selected 6-page papers from the ISAP2018 Conference. These articles were peer reviewed according to the highest scientific standards. The contributions in this issue represent latest advances in research to enhance the performance of asphalt pavements and to explore cutting edge technologies to make them more durable, resilient, and sustainable. Case studies of two national highways are also included and illustrate the importance of the implementation of proper material characterization and field monitoring strategies.

The ISAP2018 was coordinated with the activities of the ISAP Technical Committees: Asphalt Pavement and Environment (APE) and Pavement Field Evaluation (PFE). The organization of ISAP2018 conference was undertaken by Jorge B. Soares (Conference Chairperson, Federal University of Ceará), Kamilla Vasconcelos (Conference Co-chairperson, University of São Paulo), Francisco Thiago S. Aragão (Conference Co-chairperson, Federal University of Rio de Janeiro), Luis Alberto Nascimento (Conference Co-chairperson, CENPES/PETROBRAS), and Gabriele Tebaldi (Chairman of the Conference Scientific Committee, University of Parma and University of Florida).

The editors would like to acknowledge the support of infraTest ${ }^{\circledR}$ Testing Systems, which sponsored the publication of this special issue of Transportes. 